\title{
Continuous enrichment culture and molecular monitoring to investigate the microbial diversity of thermophiles inhabiting the deep-sea hydrothermal ecosystems
}

\author{
Anne Postec ${ }^{1,{ }^{\star}}$, Laurent Urios $^{1}$, Françoise Lesongeur $^{1}$, Bernard Ollivier $^{2}$, \\ Joël Querellou ${ }^{1}$, Anne Godfroy ${ }^{1}$
}

(1) UMR 6197, Laboratoire de Microbiologie des Environnements Extrêmes, IFREMER, Centre de Brest, BP 70, 29280 Plouzané, France

(2) Laboratoire de Microbiologie, Institut de Recherche pour le Développement, UR 101, IFR-BAIM, Universités de Provence et de la Méditerranée, ESIL case 925, 163 Avenue de Luminy, 13288 Marseille Cedex 9, France

* : Corresponding author : anne.postec@ifremer.fr

\begin{abstract}
:
The microflora developing during a continuous enrichment culture from a hydrothermal chimney sample was investigated by molecular methods. The culture was performed in a gas-lift bioreactor under anaerobic conditions, at $90^{\circ} \mathrm{C}$ and $\mathrm{pH} 6.5$, on a complex medium containing sulfur as the terminal electron acceptor. Archaeal and bacterial diversity was studied. Microorganisms affiliated with the genera Pyrococcus, Marinitoga, and Bacillus were detected through DGGE analysis of 16S rDNA. Additional sequences phylogenetically related to Thermococcus and -Proteobacteria were detected by cloning and sequencing of $16 \mathrm{~S}$ rDNA from two samples of the enrichment culture. In comparison, the sequences retrieved from cloning analysis from an enrichment culture performed in a flask (batch condition) using the same culture medium showed that only members of the genus Thermococcus were cultivated. Therefore, continuous enrichment culture using the gas-lift bioreactor can be considered as an efficient and improved method for investigating microbial communities originating from deep-sea hydrothermal vents.
\end{abstract}




\section{Introduction}

Identifying the populations constitutive of microbial communities is still a major challenge. It was estimated that 90 to $99 \%$ of the organisms remained uncultivated [6], due to difficulties in reproducing their physiological niche in the laboratory. The results of molecular approaches dedicated to deep-sea hydrothermal systems were mainly obtained by 16S rDNA analysis. They showed the wealth of microbial diversity [21, 28] and the limitations of traditional cultivation techniques in improving our knowledge of the biodiversity inhabiting deep-sea hydrothermal vents. Nevertheless, in fine, cultivation remains necessary to describe new microbial representatives thriving in hydrothermal deep-sea vents $[15,23]$ and allows the study of in situ living microorganisms that express their physiological properties as members of the natural microflora. Since current culture techniques do not always satisfy the need of providing a good balanced picture of the microflora composition, future developments in the study of bacterial diversity should include improvements in the culture methods to approach the physico-chemical conditions of natural habitats [22]. Traditional culture attempts from hydrothermal samples were usually performed by enrichment cultures in flasks. In this study, an enrichment culture was performed in a 2-litre gas-lift bioreactor. This equipment was previously developed to grow anaerobic hyperthermophilic microorganisms [24], to study the metabolism of members of the order Thermococcales [14], and to develop a minimal medium for growth of these hyperthermophiles [25]. Enrichment culture in the gas-lift bioreactor was expected to allow the growth of microorganisms (i) poorly represented in the ecosystem, (ii) exhibiting a long latency phase or (iii) having not previously been cultivated so far. This could be induced by the continuous substrate supply, gas elimination by $\mathrm{N}_{2}$ sparging, $\mathrm{pH}$ regulation, and long incubation time (during several weeks). It has already been reported that bacterial and archaeal populations' dynamics can be monitored in anaerobic digester according to $16 \mathrm{~S}$ rRNA, and $16 \mathrm{~S}$ rDNA sequences, and changes in the composition of the microflora were then highlighted $[9,17]$. In this paper, we describe the use of a gas-lift bioreactor to perform an enrichment culture in controlled conditions. Amongst molecular tools available, denaturing gradient gel electrophoresis (DGGE) and 16S rDNA cloning analysis of two culture samples were chosen to investigate microbial dynamics and diversity. In comparison, enrichment cultures in flasks were performed in the same culture medium and the microflora cultivated was investigated through cloning and sequencing analysis. 


\section{Materials and Methods}

Samples. During the ATOS cruise (European project VENTOX) located on the Mid-Atlantic Ridge (MAR), on the Rainbow field $\left(36^{\circ} 13^{\prime} \mathrm{N} 33^{\circ} 54 \mathrm{~W}\right)$ at $2275 \mathrm{~m}$ depth, an active black smoker was collected by the Remote Operated Vehicule (ROV) Victor, and brought to the surface in a decontaminated insulated box. On board, subsamples of the chimney were crushed into an anaerobic chamber and stored in sterile serum vials filled with sterile seawater containing $0.5 \mathrm{mg} \mathrm{l}^{-1}$ of $\mathrm{Na}_{2} \mathrm{~S}$. The subsamples were pooled to represent the whole chimney, and used as inoculum at $2 \%$.

\section{Enrichment conditions in bioreactor and culture monitoring}

Medium. The growth medium was the modified SME medium [29] in which yeast and peptone were replaced by $1 \mathrm{~g} \mathrm{l}^{-1}$ yeast extract; $0.5 \mathrm{~g} \mathrm{l}^{-1}$ casaminoacids; $0.4 \mathrm{~g} \mathrm{l}^{-1}$ glucose; $0.4 \mathrm{~g} \mathrm{l}^{-1}$ dextrin (from corn); $0.2 \mathrm{~g} \mathrm{l}^{-1} \mathrm{D}(+)$ galactose; $0.2 \mathrm{~g} \mathrm{l}^{-1}$ dextran; $0.1 \mathrm{~g} \mathrm{l}^{-1}$ glycogen; $0.2 \mathrm{~g} \mathrm{l}^{-1}$ pyruvate, $0.1 \mathrm{~g} \mathrm{l}^{-1}$ acetate and $3 \mathrm{~g} \mathrm{l}^{-1}$ colloidal sulphur.

Culture conditions. The medium was sterilized by filtration (Sartroban, $0.22 \mu \mathrm{m}$ ) in 201 Nalgene bottle containing the colloidal sulphur, previously sterilized by heating twice at $100^{\circ} \mathrm{C}$ for $30 \mathrm{~min}$ on two successive days. The culture was performed at $90^{\circ} \mathrm{C}$ and $\mathrm{pH} 6.5$. The temperature was regulated and the $\mathrm{pH}$ was controlled by addition of either $1 \mathrm{~N}$ $\mathrm{NaOH}$ or $1 \mathrm{~N} \mathrm{HCl}$ solutions. Moreover, the culture was sparged with $\mathrm{N}_{2}\left(0.1 \mathrm{v} \cdot \mathrm{v}^{-1} \cdot \mathrm{min}^{-1}\right)$ to maintain anaerobic conditions, and to eliminate possible volatile fermentation end products that might inhibit the growth of fermentative microorganisms.

Culture monitoring. The culture was maintained during 50 days. Culture samples from the bioreactor were first collected every 3 hours during the $34 \mathrm{~h}$-batch culture, and then daily during the continuous culture, representing a total of 51 samples. Cell concentration of each sample was determined by direct cell counting, using a Thoma chamber (0.02 mm depth) with an Olympus BH2 phase contrast microscope $(\times 400)$.

Sample preservation. For each sampling, eight $1.8 \mathrm{ml}$-cryotubes of culture were frozen at $-20^{\circ} \mathrm{C}$ in the presence of $5 \%$

DMSO. Cells were also recovered from $15 \mathrm{ml}$ of culture by centrifugation (30 min at $8000 \times \mathrm{g}$ ), washed with $23 \mathrm{~g} \mathrm{l}^{-1}$ sterile $\mathrm{NaCl}$, and the cell pellets were stored at $-20^{\circ} \mathrm{C}$.

Enrichment conditions in flask and culture monitoring. Enrichment cultures were performed in $100 \mathrm{ml}$ serum vials as previously described [13], with the same medium, temperature and $\mathrm{pH}$ as in the bioreactor. Cell pellets for molecular analysis were recovered from $15 \mathrm{ml}$ of culture in flask, after $45 \mathrm{~h}$ and $65 \mathrm{~h}$ of incubation, and also after a $20 \mathrm{~h}$ subculture from the first $45 \mathrm{~h}$ culture. 
DNA extraction. Extractions were performed on frozen cells pellets following the extraction protocol of Alain et al [2].

16S rDNA PCR-DGGE analysis. The variable v3 region of 16S rRNA gene from extracted DNA was amplified using specific primers corresponding to both archaeal and bacterial domains. Archaeal 16S rRNA genes were amplified using primers 344F-GC and 915R [7]. Bacterial 16S rRNA genes were amplified using primers 341F-GC and 907R [19, 20]. PCR procedure and analysis of the fragments by DGGE using Bio-Rad Dcode apparatus were previously described by Muyzer et al. [19]. Samples were loaded onto $8 \%(\mathrm{w} / \mathrm{v})$ polyacrylamide gels, in TAE-1× with a denaturing gradient ranging from $50 \%$ to $80 \%$ urea-formamide (UF) for archaeal DNA analysis, and from $35 \%$ to $80 \%$ UF for bacterial DNA analysis (100\% corresponding to $7 \mathrm{M}$ urea and $40 \%(\mathrm{v} / \mathrm{v})$ formamide). Electrophoresis was run for $16 \mathrm{~h}$ at $70 \mathrm{~V}$ and stained with ethidium bromide. DGGE bands were cut out with a sterile blade. The DNA of each fragment was eluted overnight at $4^{\circ} \mathrm{C}$ in $50 \mu \mathrm{l}$ sterile and purified water. One microliter of the eluted DNA of each DGGE band was reamplified, using the same conditions as above. Running an aliquot of the PCR product, in DGGE gels as described above, checked the success of this operation. The PCR products, which yielded a single band co-migrating with the original band, were then purified on a QIAquick silica-gel spin column (Qiagen) and sequenced.

16S rDNA PCR-cloning analysis. Archaeal and bacterial DNAs were amplified using universal primers and PCR procedure previously described [31]. PCR products were then checked on a $0.8 \%(\mathrm{w} / \mathrm{v})$ agarose gel and directly cloned using the TOPO TA Cloning ${ }^{\circledR}$ kit (Invitrogen) according to the manufacturer's instructions. Clone libraries were constructed by transforming E. coli TOP10F' cells. An archaeal and a bacterial libraries were constructed for two culture samples collected after 7 days (T7) and 28 days (T28) of culture. Three archaeal libraries were constructed from the enrichment cultures in flask.

$16 S$ rDNA sequencing and phylogenetic analysis. DNA fragments obtained by DGGE were sequenced by Genome Express S.A. (Grenoble, France). Clones were cultivated overnight at $37^{\circ} \mathrm{C}$ on Deepwell microplates, in LB $2 \mathrm{X}$ medium. Plasmids were extracted using Plasmid Miniprep Kits (Qiagen) and partially sequenced. Sequences were compared to those available in databases, using the BLAST [5] network service to determine phylogenetic affiliations, aligned with the rDNA sequences from the RDP (Ribosomal Database Project), using the GCG CLUSTALW program [30], and refined manually using the SEAVIEW program [12]. Trees were constructed using the PHYLO_WIN program, on the basis of evolutionary distance [27] and maximum likelihood methods [11]. The robustness of inferred topologies was tested by the bootstrap resampling of trees [10] calculated on the basis of the evolutionary distance, neighbor-joining algorithm with Jukes-Cantor correction [16] and maximum likelihood. If related sequences displayed 
more than $97 \%$ sequence similarity, only one of the sequences was retained for phylogenetic analysis. One representative of each unique phylotype was completely sequenced.

\section{Results}

Monitoring of the enrichment culture in bioreactor. The bioreactor was inoculated at $2 \%$ (vol/vol) with a chimney sample suspension. Very low cell densities were measured during the first 34 hours of batch. Then a dilution rate of $0.04 \mathrm{~h}^{-1}\left(80 \mathrm{ml} \mathrm{h}^{-1}\right)$ was applied. The period of batch culture was fixed arbitrarily in order to avoid washing out of the cells before they had become adapted to the growth conditions. Cell density stabilized at around $5 \times 10^{5}$ cell $\mathrm{ml}^{-1}$ until $105 \mathrm{~h}$ of culture. By $124 \mathrm{~h}$, cell number had increased to $1.8 \times 10^{8}$ cell ml-1 This was associated with $\mathrm{H}_{2} \mathrm{~S}$ production (detected using Zn acetate strips). Amongst observed morphologies, coccoid cells, single or in pairs, were dominant throughout the enrichment culture. Short rod-shaped cells appeared singly or in chains within an outer sheath-like structure, comparable to the 'toga' specific to Thermotogales [1]. From $350 \mathrm{~h}$ until the end of the culture, only single or paired coccoid cells were observed.

DGGE monitoring of the culture in bioreactor. Total DNA was successfully extracted on samples between the $4^{\text {th }}$ to the $50^{\text {th }}$ day of culture. From the earlier samples, difficulties in DNA extraction were encountered, probably due to the very low cell density. The DGGE procedure was tested with $16 \mathrm{~S}$ rDNA fragments from reference strains. Conditions were optimised to analyse separately archaeal and bacterial fragments. Fragments from the two Pyrococcus species, P. abyssi and P. glycovorans, could not be separated (data not shown). Archaeal 16S rDNA gene were amplified with the DGGE primers from 29 distinct culture samples covering all the culture duration. One band was obtained for each sample, at the same height in all cases. 12 bands were excised, amplified by PCR, checked on a DGGE gel, and directly sequenced. A similarity of more than $97 \%$ was shared between those sequences on about 320 bp of the variable v3 region of the $16 \mathrm{~S}$ rRNA gene. The type sequence Apa10 (Table 1) presented 100\% identity on 417 bp with seven matching organisms from the BLAST analysis, all belonging to the Pyrococcus genera. As a result only sequences related to Pyrococcus could be detected throughout the culture. Using the same procedure, the v3 region of bacterial 16S rDNAs was amplified with specific DGGE primers (Table 1). Bacterial 16S rDNA genes were amplified successfully from nine distinct culture samples, from day 5 to day 35. Several dense bands were obtained at different heights. Amongst the 14 sequences obtained from excised bands, five of them represented by the sequence Apb7 (Table 1), matched by a BLAST analysis with sequences of the Bacillus genus. These sequences were retrieved from samples between day 5 and 9. Nine sequences obtained from excised bands were closely related to the genus Marinitoga and 
were retrieved between day 7 and 35. DGGE analysis revealed the phylogenetic affiliation of the dominant cultivated strains and showed a larger diversity among Bacteria than Archaea.

Cloning-sequencing analysis of the culture in bioreactor. In the two archaeal libraries corresponding to the two culture samples $\mathrm{T} 7$ and T28, all the sequences belonged to the order Thermococcales (Fig. 2.). Within 59 clones partially sequenced from the earlier culture sample T7, two phylotypes were identified and were closely related to the genus Pyrococcus. The type sequences T7a-44 and T7a-60 shared 99\% of similarity with Pyrococcus horikoshii as well as with Pyrococcus abyssi and Pyrococcus furiosus based on about $1500 \mathrm{pb}$. However, the complete sequences of these two representative clones shared only $96 \%$ of similarity, so that two distinct Pyrococcus species could have been cultivated. Within 49 clones partially sequenced from the second culture sample T28, 4\% represented by the sequence type T28a-17 were related to the genus Pyrococcus, while $96 \%$ were closely related to the genus Thermococcus, represented by the sequence T28a-18 (Fig. 2.). The nearest strain according to the BLAST analysis was "Thermococcus sulfurophilus" (AF394925). Among the T7 bacterial library, six phylotypes were defined: one within the $\gamma$ Proteobacteria ( $3 \%$ of the sequences), two within the $\varepsilon$-Proteobacteria ( $38 \%$ of the sequences), two within the Bacillus/Clostridiales group (36\% of the sequences), and one within the Thermotogales order ( $23 \%$ of the sequences) (Fig. 3.). Interestingly, all the $\varepsilon$-Proteobacteria sequences were affiliated to uncultured bacteria, all originated from deep-sea hydrothermal environments. Within the Bacillus/Clostridiales group and the Thermotogales order, the retrieved sequences were related (with $99 \%$ of identity) to Caminicella sporogenes and Marinitoga piezophila respectively. Within the T28 bacterial library, $17 \%$ of the sequences were affiliated to uncultured $\varepsilon$-Proteobacteria. Nine per cent of the sequences were closely related to the genus Caminicella, and $61 \%$ to the genus Marinitoga. No sequences related to $\gamma$-Proteobacteria were retrieved in the T28 bacterial library and $13 \%$ of the sequences were assigned to deep-sea hydrothermal sequences of the Aquificales order, which were not retrieved in the earlier culture sample.

Cloning-sequencing analysis of the cultures in flask. The medium was inoculated at $2 \%$ (vol/vol) with the same suspension of chimney sample. Total DNA was successfully extracted from the enrichment cultures in flask, after $45 \mathrm{~h}$ and $65 \mathrm{~h}$ of incubation at $90^{\circ} \mathrm{C}$, and from a $20 \mathrm{~h}$ subculture from the $45 \mathrm{~h}$ culture. Only archaeal $16 \mathrm{~S}$ rRNA gene could be amplified. Three archaeal clone libraries were constructed and 64 clones of each were sequenced. As a result, the sequences obtained were all affiliated to the Thermococcus genus. The nearest described species according to the BLAST analysis was Thermococcus barophilus (AY099172). No Pyrococcus neither bacteria could be detected among the strains cultivated in batch. 


\section{Discussion}

Compared to conventional enrichment culture in batch, a novel approach was used to investigate the microbial diversity of a hydrothermal vent chimney sample. The use of the gas-lift bioreactor technology to perform a continuous culture provide a controlled laboratory environment for the enrichment and cultivation of different microbial groups in hyperthermophilic conditions $\left(90^{\circ} \mathrm{C}\right) . \mathrm{pH}$ and temperature were continuously monitored and adjusted. In addition, the culture was continuously sparged with $\mathrm{N}_{2}$, thus homogenising the medium and also eliminating possible toxic products from fermentation processes. Since the medium was continually renewed, the enrichment culture could be maintained a long time during which the analysis of the microbial population was performed. A dynamics in the cultivated microflora could be highlighted all through the enrichment culture in bioreactor, as it was already observed in anaerobic digestors $[8,17]$. Actually, an evolution of the cell morphologies including rods and cocci could be observed, and modifications of the microbial diversity was ascertained through $16 \mathrm{~S}$ rDNA sequences analysis.

The diversity of microbial population was first assessed using the DGGE technique. Here we demonstrate the efficiency of the DGGE technique for studying thermophilic Archaea and Bacteria diversity and monitoring the population dynamics. Using this technique, we demonstrated that $16 \mathrm{~S}$ rDNA sequences, retrieved from the continuous culture, were closely related to members of the genera Bacillus, Marinitoga and Pyrococcus. Cloning analysis of the microbial population was performed on two culture samples at day 7 (T7) and at day 28 (T28). Similarly to the DGGE technique, Pyrococcus, Caminicella, and Marinitoga related sequences were detected at day 7, whereas Pyrococcus and Marinitoga were detected at day 28. Cloning analysis revealed a larger biodiversity than DGGE, since members of Thermococcus, $\gamma$ - and $\varepsilon$-Proteobacteria and Aquificales were only detected by cloning. Therefore our results confirm the need for combining several molecular methods to avoid the bias inherent in each one and to have a better knowledge of the microbial diversity.

All the archaeal sequences, detected by DGGE and by cloning, were phylogenetically related to the order Thermococcales, and more specifically to the genera Pyrococcus and Thermococcus, known as heterotrophic and hyperthermophilic microorganisms. Interestingly, 16S rDNA sequences analysis showed that the Thermococcus strain enriched in flask was different from the one detected in bioreactor. Actually, the closest relative of retrieved Thermococcus 16S rDNA sequences from cultures in flask was Thermococcus barophilus [18], whereas sequences retrieved from the bioreactor were close to "Thermococcus sulfurophilus", a sulphur-reducing archaeon also originated from the Rainbow site. These results emphasise the interest of using a continuous bioreactor to enrich cultures since providing evidence of a different diversity of Thermococcus strains as compared to that obtained in batch conditions. Beside their detection in the continuous bioreactor by molecular techniques, the two novel archaeal strains belonging to the genera Pyrococcus and Thermococcus have also been isolated by the dilution-to-extinction technique [1]. 
Experiments conducted to look for the occurrence of microorganisms of the domain Bacteria indicated that no bacterial sequences could be obtained from the batch cultures in flask. In contrast, studies within the continuous bioreactor revealed a large bacterial diversity through the cloning-sequencing analysis of $16 \mathrm{~S}$ rDNA (Fig. 2.). This again confirms the interest of using a different methodological approach to investigate the biodiversity of microorganisms inhabiting deep-sea hydrothermal vents. Amongst the $16 \mathrm{~S}$ rDNA sequences detected in this study, close relatives of Caminicella sporogenes [3] and Marinitoga piezophila [1] were found. These species are known to grow at temperatures much lower than $90^{\circ} \mathrm{C}$ (maximal growth temperature of $65^{\circ} \mathrm{C}$ and $75^{\circ} \mathrm{C}$ respectively). The presence of these bacteria at $90^{\circ} \mathrm{C}$ may indicate (i) the existence of unknown species belonging to both genera and thriving in these conditions, (ii) a possible growth of close representatives of previously isolated Caminicella and Marinitoga spp. under hyperthermophilic conditions due to thermoprotective molecules released by the other members of the enrichment culture, or (iii) unknown interactions between bacteria and archaeons. Many sequences retrieved during this study were affiliated to uncultivated microorganisms belonging to the $\varepsilon$-Proteobacteria. They were in particular closely related to the hydrothermal sequences VC2.1 Bac31 and VC2.1 Bac1, from the Snake Pit deep-sea vent site, on the Mid-Atlantic Ridge [26]. In all the deep-sea vent microbial communities studied to date, $\varepsilon$-Proteobacteria phylotypes were shown to be dominant, accounting for $40-98 \%$ of the bacterial clone libraries. The $\varepsilon$-Proteobacteria detected in our enrichment culture at $90^{\circ} \mathrm{C}$ were adapted at higher temperatures than those described for all $\varepsilon$-Proteobacteria characterised so far, which do not grow over $70^{\circ} \mathrm{C}$ in pure culture [4]. These results confirm the importance of pursuing efforts for isolating new populations of hyperthermophiles from their natural environments. With regards to numerous reports, it is now more and more obvious that the combination of both molecular approach and cultivation is the best way so far to assess the microbial diversity of hydrothermal vent chimney. Molecular studies suffer from the drawback that metabolic properties can only rarely be inferred from the $16 \mathrm{~S}$ rRNA sequences data alone. Likewise, limitations of molecular tools must be kept in mind [2]. In this respect, the use of both cultivation and molecular methods may help to answer these questions.

The gas-lift bioreactor technology appears therefore to be an improved method to perform enrichment cultures. During the enrichment culture in the continuous bioreactor, different microorganisms were cultivated and a much larger diversity was exhibited as compared to cultures performed in flasks (batch conditions). Even new microorganisms inhabiting deep-sea hydrothermal vent could be evidenced, and isolation of two strains by subcultures in flask has already been successful. The use of the bioreactor for further enrichment experiments should contribute to better simulate hydrothermal physiological niches in the laboratory, and to reproduce environmental perturbations in vitro (temperature, $\mathrm{pH}, \mathrm{O}_{2}$, nature and concentration of the substrates ...). This should improve our understanding of the key ecological roles played by microorganisms in the hydrothermal ecosystems. 


\section{Nucleotide sequence accession numbers}

The EMBL accession numbers of the sequences used in this study are AJ585953 to AJ585977.

\section{ACKNOWLEDGEMENTS}

The authors want to thank P.M. Sarradin, chief scientist of the ATOS cruise, as well as the captain and crew of the Atalante and the Victor team. We thank Dr P. Roger and L. Casalot (IRD) for revising the manuscript. This work was supported by Ifremer, European VENTOX Program and Région Bretagne.

\section{Literature cited}

1. Alain K, Marteinsson VT, Miroshnichenko ML, Bonch-Osmolovskaya EA, Prieur D, Birrien JL (2002) Marinitoga piezophila sp. nov., a rod-shaped, thermo-piezophilic bacterium isolated under high hydrostatic pressure from a deep-sea hydrothermal vent. Int J Syst Evol Microbiol 52:1331-1339

2. Alain K, Olagnon M, Desbruyeres D, Page A, Barbier G, Juniper SK, Querellou J, Cambon-Bonavita MA (2002) Phylogenetic characterization of the bacterial assemblage associated with mucous secretions of the hydrothermal vent polychaete Paralvinella palmiformis. FEMS Microbiol Ecol 42:463-476

3. Alain K, Pignet P, Zbinden M, Quillevere M, Duchiron F, Donval JP, Lesongeur F, Raguenes G, Crassous P, Querellou J, Cambon-Bonavita MA (2002) Caminicella sporogenes gen. nov., sp. nov., a novel thermophilic sporeforming bacterium isolated from an East-Pacific Rise hydrothermal vent. Int J Syst Evol Microbiol 52:1621-1628

4. Alain K, Querellou J, Lesongeur F, Pignet P, Crassous P, Raguenes G, Cueff V, Cambon-Bonavita MA (2002) Caminibacter hydrogeniphilus gen. nov., sp. nov., a novel thermophilic, hydrogen-oxidizing bacterium isolated from an East Pacific Rise hydrothermal vent. Int J Syst Evol Microbiol 52:1317-1323

5. Altschul SF, Gish W, Miller W, Meyers EW, Lipman DJ (1990) Basic Local Alignment Search Tool. J Mol Biol 215:403-410

6. Amann RI, Ludwig W, Schleifer KH (1995) Phylogenetic identification and in situ detection of individual microbial cells without cultivation. Microbiol Rev 59:143-169

7. Casamayor EO, Schäfer H, Baneras L, Pedros-Alio C, Muyzer G (2000) Identification and spatio-temporal differences between microbial assemblages from two neighboring sulfurous lake : Comparison by microscopy and denaturating gradient gel electrophoresis. Appl Environ Microbiol 66:499-508

8. Delbes C, Moletta R, Godon JJ (2000) Monitoring of activity dynamics of an anaerobic digester bacterial community using 16S rRNA polymerase chain reaction - single-strand conformation polymorphism analysis. Environ Microbiol 2:506-515

9. Delbes C, Moletta R, Godon JJ (2001) Bacterial and archaeal 16S rDNA and 16S rRNA dynamics during an acetate crisis in an anaerobic digestor ecosystem. FEMS Microbiol Ecol 35:19-26

10. Felsentein J (1985) Confidence limits on phylogenies: an approach using the bootstrap. Evolution 39:783-791

11. Felsentein J (1981) Evolutionary trees from DNA sequences: a maximum likelihood approach. J Mol Evol 17:368376

12. Galtier N, Gouy M, Gautier C (1996) SEAVIEW and PHYLO_WIN: two graphic tools for sequence alignment and molecular phylogeny. CABIOS 12:543-548

13. Godfroy A, Meunier JR, Guezennec J, Lesongeur F, Raguénès G, Rimbault A, Barbier G (1996) Thermococcus fumicolans sp. nov. a new hyperthermophilic archaeum isolated from deep-sea hydrothermal vent in North Fiji bassin. Int J Syst Bacteriol 46:1113-1119 
14. Godfroy A, Raven NDH, Sharp RJ (2000) Physiology and continuous culture of the hyperthermophilic deep-sea vent archaeon Pyrococcus abyssi ST549. FEMS Microbiol Lett 186:127-132

15. Jeanthon C (2000) Molecular ecology of hydrothermal vent microbial communities. Antonie van Leeuwenhoek $77: 117-133$

16. Jukes TH, Cantor CR (1969) Evolution of protein molecules. In H N Munro, editor, Mammalian Protein Metabolism, Academic Press, 21-132

17. Leclerc M, Delbes C, Moletta R, Godon JJ (2001) Single strand conformation polymorphism monitoring of $16 \mathrm{~S}$ rDNA Archaea during start-up of an anaerobic digester. FEMS Microbiol Ecol 34:213-220

18. Marteinsson V, Birrien J, Reysenbach A, Vernet M, Marie D, Gambacorta A, Messner P, Sleytr U, Prieur D (1999) Thermococcus barophilus sp. nov., a new barophilic and hyperthermophilic archaeon isolated under high hydrostatic pressure from a deep-sea hydrothermal vent. Int J Syst Bacteriol 49:351-359

19. Muyzer G, De Waal EC, Uitterlinden AG (1993) Profiling of complex microbial populations by denaturing gradient gel electrophoresis analysis of polymerase chain reaction- amplified genes coding for 16S rRNA. Appl Environ Microbiol 59:695-700

20. Muyzer G, Smalla K (1998) Application of denaturing gradient gel electrophoresis (DGGE) and temperature gradient gel electrophoresis (TGGE) in microbial ecology. Antonie van Leeuwenhoek 73:127-141

21. Nercessian O, Reysenbach AL, Prieur D, Jeanthon C (2003) Archaeal diversity associated with in situ samplers deployed on hydrothermal vents on the East Pacific Rise ( $\left.13^{\circ} \mathrm{N}\right)$. Environ Microbiol 5:492-502

22. Palleroni NJ (1997) Prokaryotic diversity and the importance of culturing. Antonie van Leeuwenhoek 72:3-19

23. Querellou J, Alain K, Cambon-Bonavita M-A (2001) Thermophiles from deep-sea hydrothermal vents. Vie Milieu $51: 161-172$

24. Raven N, Ladwa N, Sharp R (1992) Continuous culture of the hyperthermophilic archaeum Pyrococcus furiosus. Appl Microbiol Biotechnol 38:263-267

25. Raven NDH, Sharp RJ (1997) Development of defined and minimal media for the growth of the hyperthermophilic archaeon Pyrococcus furiosus Vc1. FEMS Microbiol Lett 146:135-141

26. Reysenbach AL, Longnecker K, Kirshtein J (2000) Novel bacterial and archaeal lineages from an in situ growth chamber deployed at a Mid-Atlantic ridge hydrothermal vent. Appl Environ Microbiol 66:3798-3806

27. Saitou N, Nei M (1987) The neighbor-joining method: a new method for reconstructing phylogenetic trees. Mol Biol Evol 4:406-425

28. Schrenk MO, Kelley DS, Delaney JR, Baross JA (2003) Incidence and diversity of microorganisms within the walls of an active deep-sea sulfide chimney. Appl Environ Microbiol 69:3580-3592

29. Sharp RJ, Raven NDH. 1997. Isolation and growth of hyperthermophiles, p. 23-51. In P. M. Rhodes and P. F. Stanbury (ed.), Applied Microbial Physiology : A practical approach. IRL Press, Oxford University press.

30. Thompson J, Higgins D, Gibson T (1994) CLUSTAL W: improving the sensitivity of progressive multiple sequence alignment through sequence weighting, position-specific gap penalties and weight matrix choice. Nucleic Acids Res 22:4673-4680

31. Wery N, Cambon-Bonavita MA, Lesongeur F, Barbier G (2002) Diversity of anaerobic heterotrophic thermophiles isolated from deep-sea hydrothermal vents of the Mid-Atlantic Ridge. FEMS Microbiol Ecol 41:105-114 


\section{Figures and tables}

Table 1. Identification of bands obtained from DGGE after BLAST analysis.

Fig. 1. Phylogenetic relationship of archaeal 16S rDNA sequences as determined by neighbor-joining analysis. Palaeococcus ferriphilus was used as the outgroup. The numbers at the nodes are the bootstrap values (as percentages). Bootstrap values above $70 \%$ are displayed. For the analysis, 1402 sites were used, with 500 bootstrap replicates. Scale bar indicates the expected number of changes per sequence position.

Fig. 2. Phylogenetic relationship of bacterial 16S rDNA sequences as determined by neighbor-joining analysis. The outgroup used was Aquifex pyrophilus. The numbers at the nodes are the bootstrap values (as percentages). Bootstrap values above $70 \%$ are displayed. For the analysis, 404 sites were used, with 500 bootstrap replicates. Scale bar indicates the expected number of changes per sequence position. 
Table 1.

\begin{tabular}{cccc}
\hline Band & Number of bands associated $^{d}$ & Closest relative & \% similarity \\
\hline Apa10 $^{a}$ & 12 & Pyrococcus abyssi L19921 & 100 \\
$\mathrm{Apb}^{b}$ & 5 & Bacillus sp. USC14 AF346495 & 99 \\
$\mathrm{Apb}^{c}$ & 9 & Marinitoga piezophila AF326121 & 99 \\
\hline
\end{tabular}

${ }^{a} 417$ bp used for BLAST analysis

${ }^{b} 553 \mathrm{bp}$ used for BLAST analysis

${ }^{c} 555$ bp used for BLAST analysis

${ }^{d}$ more than $97 \%$ of similarity between the sequences of a same group 
Fig. 1.

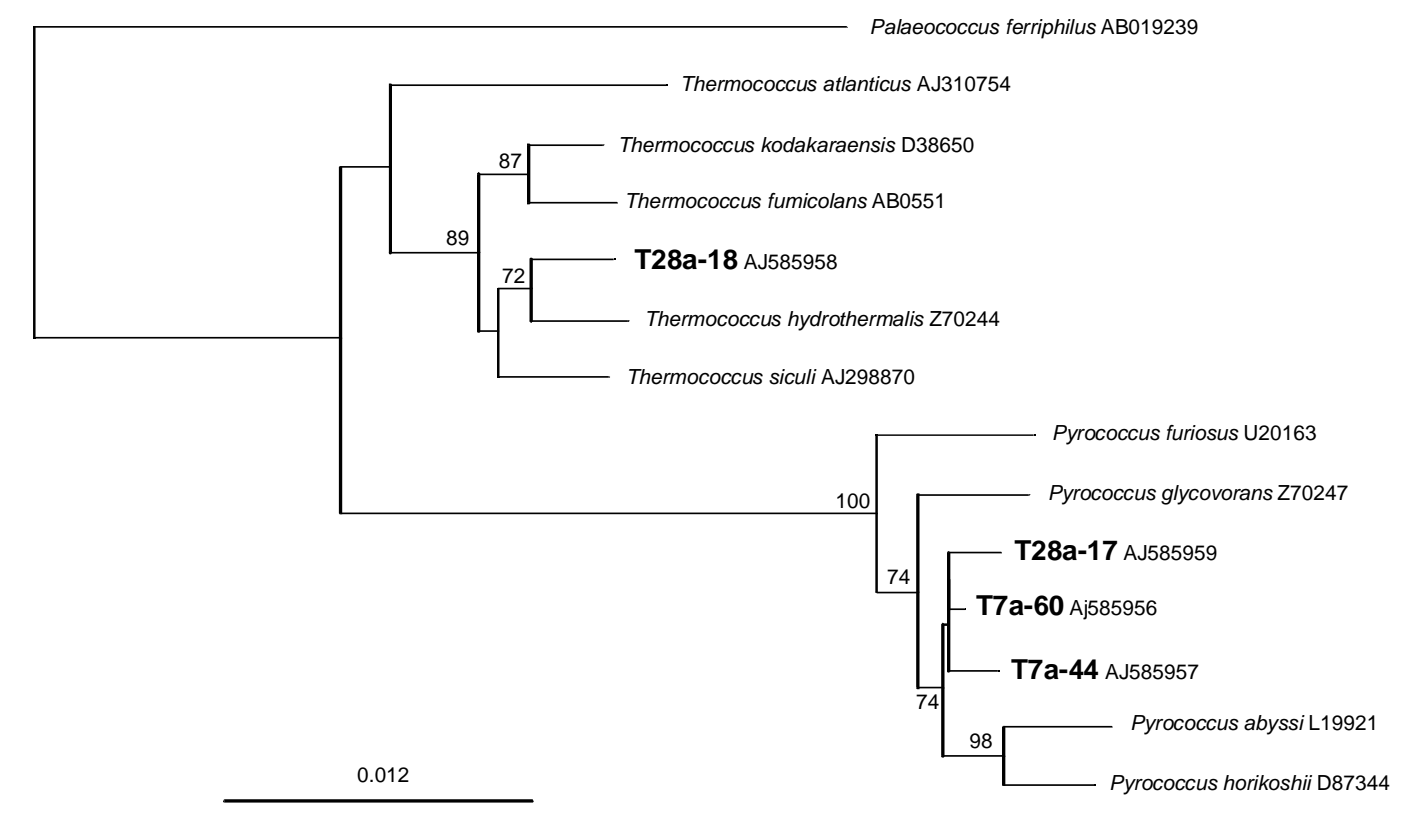


Fig. 2.

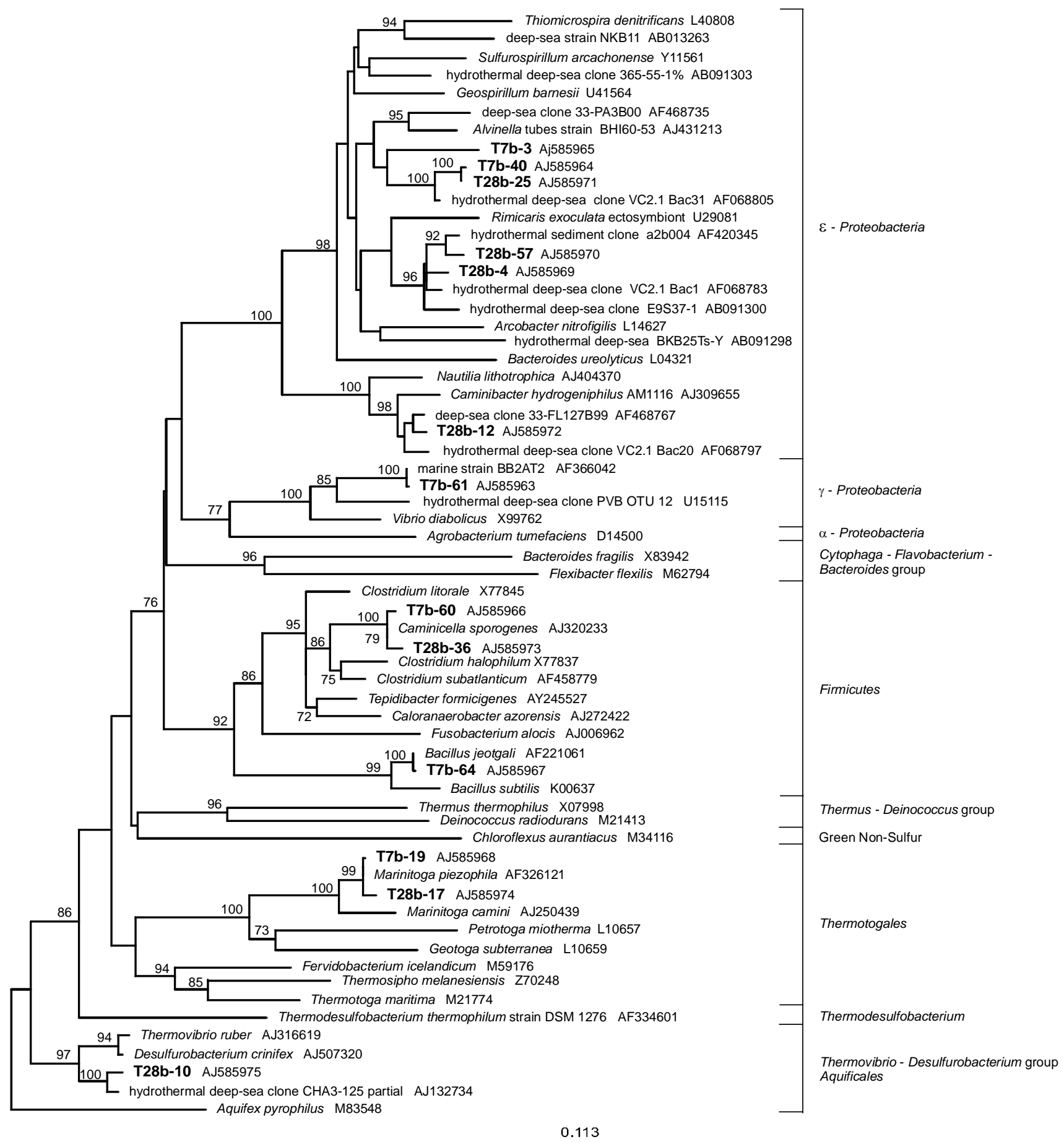

